
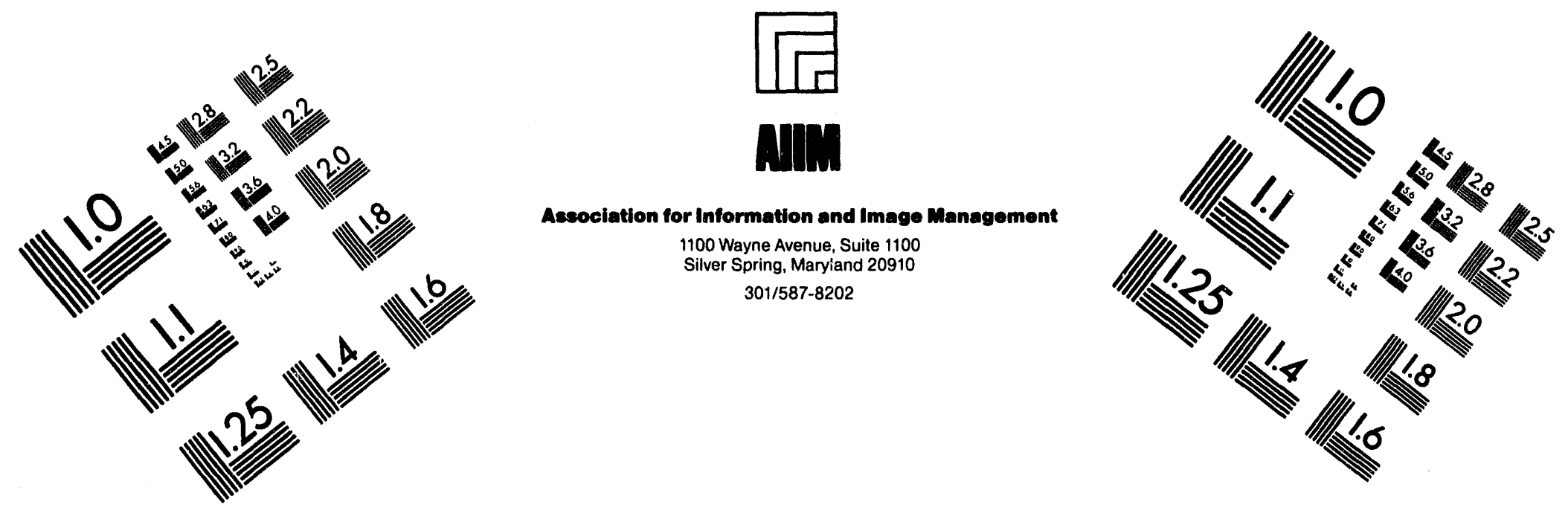

\title{
Centimeter
}

$\begin{array}{llllllllllllllll}1 & 2 & 3 & 4 & 5 & 6 & 7 & 8 & 9 & 10 & 11 & 12 & 13 & 14 & 15 & \mathrm{~mm}\end{array}$ Inches

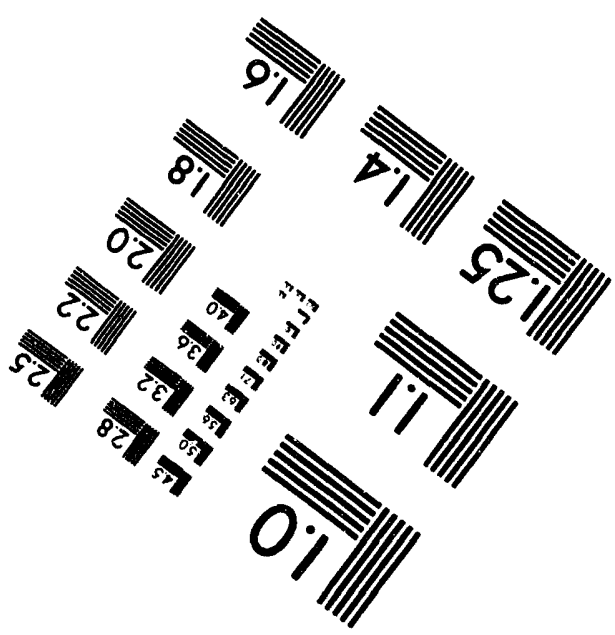

MANUFACTURED TO AIIM STANDARDS

BY APPLIED IMAGE, INC.

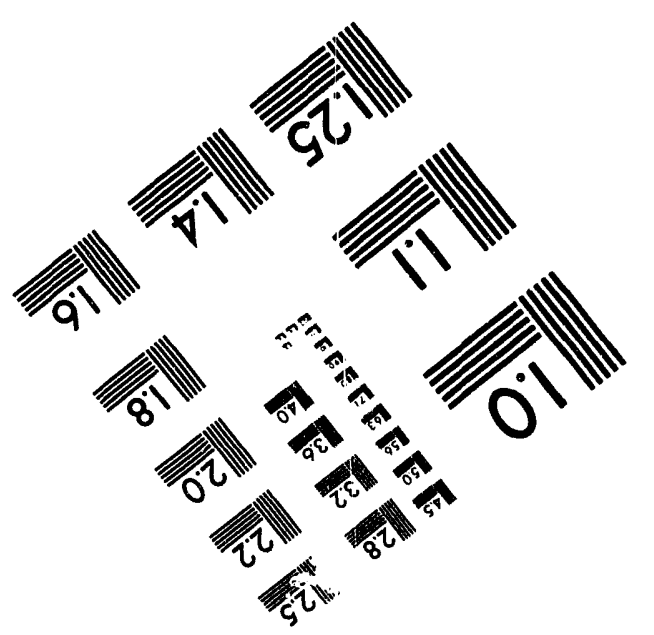



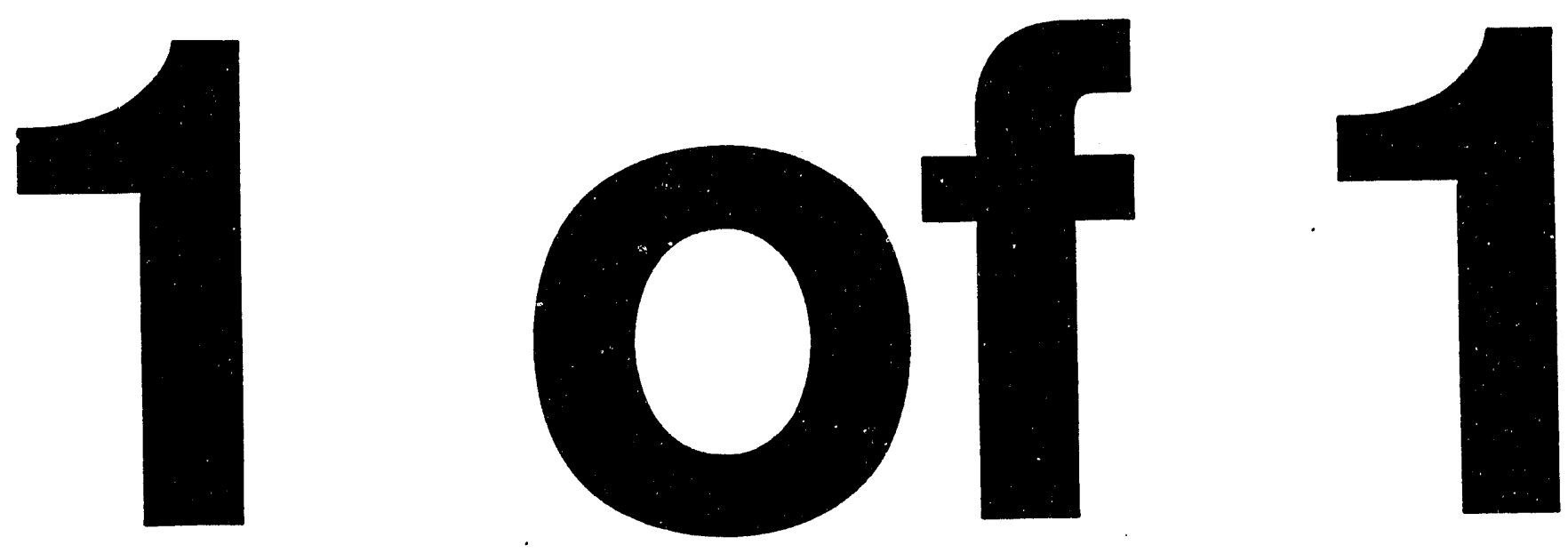

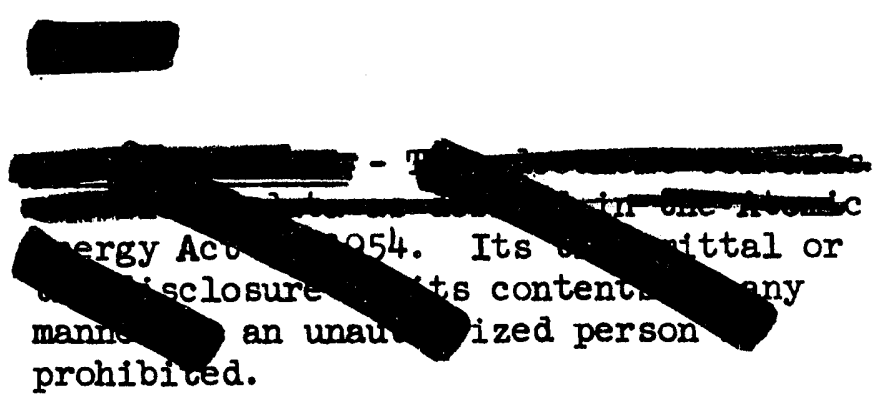

This document consists of

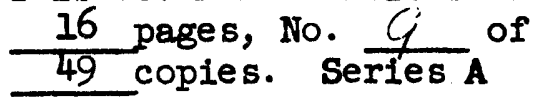

OPTIMTZATION OF K REACTOR POWER IEVEIS REIATEED

TO A ZIRCONTUM TURE REPIACEMENT PROJECT

Chestication Cenoullod and Changed To

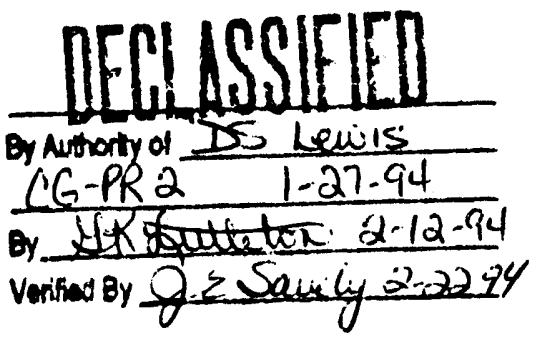

\author{
by
}

N. E. Fuller and S. M. Graves

Process Engineering Unit

Research and Engineering Section

IRRADIATION PROCESSING DEPARTMENT

November 15, 1960
1. WG Albert
2. ER Astley
3. JT Baker
4. JW Baker
5. RS Bell
6. JL Benson
7. RW Bown
8. JH Brown
9. MA Clinton
10. RG Clough
11. BR Cremer
12. WJ Ferguson
13. EJ Filip
14. NE Fulier
15. GC Fullmer
16. WJ Gartin
17. SM Graves
18. OH Greager
19. CN Gross
20. AK Hardin
21. CM Heeb
22. IW Lang
23. IC Iessor
24. CG Iewis
25. DS Lewis
26. AR Maguire
27. GL Madsen
28. NR Miller
29. SL Nelson
30. GF owsley
31. CA Priode
32. T Prudich
33. WH Radtke
34. RW Reid
35. DL Renberger
36. WD Richmond
37. GJ Rogers
38. A Russel]
39. OC Schroeder
40. IA Smith
41. HG Spencer
42. RE Trumble
43. AP Vinther
44. WW Windsheimer
45. JR Young
46. 300 Files
47. Record Center
48. Extra
49. Extra

PRELTMINARY REPORT

This report was prepared only for use within General Electric Company in the course of work under Atomic Energy Commission Contract AT(45-1) -1350. Any views or opinions expressed in the report are those of the author only. 


\section{OPTIMIZATION OF K REACTOR POWER IEVEIS RELATED TO A ZIRCONIUM TUBE REPLACEMENT PROJECT}

\section{INTRODUCTION}

The assumption of tube replacement losses can have a significant effect in the determination of optimum power levels and goal exposures. The tube replacement loss term in the reactor process optimization model $(1)$ is based on calculating the average projected tube replacement losses that will result from operation at given power and temperature conditions. Tube replacement losses associated with external corrosion, Van Stone flange failure, etc. (i.e., basically nonpower level-temperature dependent) are assumed to be miscellaneous losses and are not included in the tube replacement term. Over a period of several years the experienced tube replacement losses (due to internal corrosion) should compare reasonably well with the losses predicted by the optimization model.

Planned tube replacement project action which would require, in some cases, premature tube removal is a special situation which requires a modified approach to the prediction of tube replacement losses and to the optimization of reactor power levels prior to project action.

A method has been developed for optimizing reactor power levels and goal exposures based on any assumed calendar date for major tube replacement project action. It is the purpose of this document to discuss the general application of this method in the optimization model and illustrate the method by presenting specific application of the method to the K Reactors.

\section{SUMMARY}

The choice of a calendar date for major tube replacement project action at the $K$ Reactors can have a significant effect on the tube replacement losses and on the determination of interim optimum power levels and goal exposures.

Depending upon the assumed project date and current tube conditions, variations as large as $130 \mathrm{~kW}$ in maximum optimum tube power and $120 \mathrm{MND} / \mathrm{T}$ in optimum natural exposure are calculated. The current condition of $\mathrm{K}$ Reactor tubes has not been fully determined. Since the choice of a tube replacement project date at the $K$ Reactors and related optimum operating conditions may be directly related to the current condition of the reactor tubes, there is considerable incentive to provide improved delineation of $\mathrm{K}$ Reactor tube conditions.

\section{DISCUSSION}

\section{General}

The method currently used for predicting tube replacement losses in the reactor process optimization model is based on the assumptions of a continuous process

(I) HW-61579, Music, JF, et al; "Reactor Process Optimization, "August 17, 1959, (2). 
and that aluminum tubes will be used for several years. The tube replacement term in the optimization model essentially is designed to predict the future tube replacement losses that will occur as a result of current operating power levels and temperatures. The actual losses predicted for current operating conditions may not be experienced for several years. For example, the $\mathrm{K}$ Reactors have had virtually no tube replacement losses to date. However, the rate at which $K$ Reactor process tubes are corroding is dependent upon curreat power level operating decisions and these accruing losses represent a significant "cost" of current $\mathrm{K}$ operation.

Until recently there has been no attempt to factor the actual condition of reactor process tubes into the optimization model. Currently, tubes are being replaced for internal corrosion at the old and $C$ Reactors after approximately 30 mils of wall thickness have been removed. The tacit assumption has been made in the optimization model that whenever a total of 30 mils has collectively been removed from all reactor tubes, one process tube will require replacement. For example, if it is calculated that the total internal corrosion on all tubes in a reactor is 300 mils for a given month, then the model would estimate that 10 tubes would eventually require removal because of the operating conditions that existed during that month. This technique is considered a reasonable basis for estimating tube replacement losses for long-term reactor operation and continuing use of aluminum tubes.

Tube replacement project action which would require partial premature tube replacement would result in the interruption of the continuing process concept and a modification to the method for tube replacement loss calculations is required.

If a tentative date for project action is known, then it is possible to optimize reactor operating conditions and tube replacement losses prior to that project date based on the best available estimate of actual tube conditions.

Current Method

In order to understand the method developed for optimizing reactor operating conditions subject to a fixed tube replacement project date it is necessary to review the tube replacement loss term used in the process optimization equation. This term is programmed as follows:

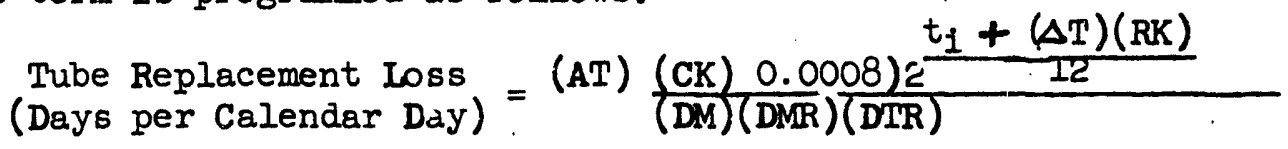

Where: $\Delta T=$ Reactor bulk outlet temperature rise

$t_{i}=$ Inlet temperauure

$\mathrm{KK}=$ Tube annulus temperature increase

Tube buik temperature increase

$\mathrm{CK}=$ Tuk - corrosion factor

$D M=30$ days per month

DMR = Mils removed from tube wall before a tube is replaced

DTR = Tube replacement rate - tubes per day (This includes non-equilibrium and valving losses) 
AT $=$ Number of active tubes in the reactor.

This equation is built upon the basic tube corrosion equation determined by

N. R. Miller: ${ }_{\text {Mils/month }}=(0.0008) 2 \frac{t_{1}+(R K)(\Delta T)}{I 2}$

If the $\Delta T$ used is the average tube $\Delta T$ (same as bulk $\Delta T$ ) and an appropriate (RK) value is used to compensate for the temperature unbalance in the tube (hotter top-of-annulus), then the total mils of tube wall thickness removed per month can be calucated for a single tube having an average outlet temperature.

Because tube corrosion increases exponentially with temperature, the average tube in the reactor corrodes faster than the corrosion rate calculated for a tube with an average outlet temperature would indicate. To adjust for this fact a (CK) term is used in the tube replacement loss equation to permit calculation of the corrosion rate for the average reactor tube using average outlet temperatures. This factor (CK) is usually in the order of 1.20 .

Multiplying by (AT), the number of active tubes, the total pile corrosion rate (mils/month) can be obtained. i.e.,

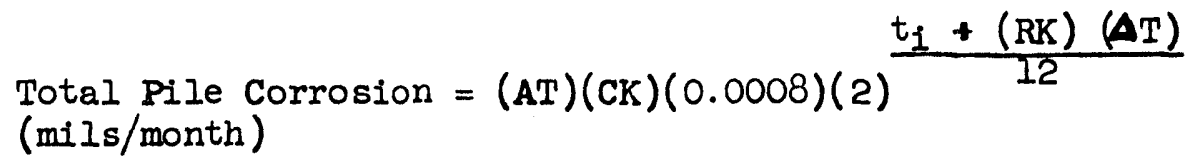

Dividing the above value by 30 gives the calculated pile corrosion in mils per day. The (DMR) term is the mils of wall thickness that can be corroded from a tube wall before replacement is advisable. For the old reactors this number has usually ranged from 25 to $30 \mathrm{mils}$. The (DTR) term in the equation is the tube replacement rate in tubes per day and includes valving and set up time as well as non-equilibrium losses. Based on actual tube removal experience at the old reactors as recorded by the Production Operation, a rate of 16 tubes/day has been determined $(2)$.

Revised Method

To examine the method for optimizing reactor operation prior to tube replacement project action, it is necessary to make two key assumptions:

1. That the project date is fixed and that regardless of tube conditions all tubes will be replaced on that date. Then, the tube replacement losses chargeable to reactor operation prior to project action are just those losses which occur because of tubes requiring replacement before the project date.

2. That the current condition of tubes in the reactor is reasonably well known.

(2) HW-65503, Radtke, WH, "A Study of Optimization Loss Constants, " June 1, 1960, (andon). 


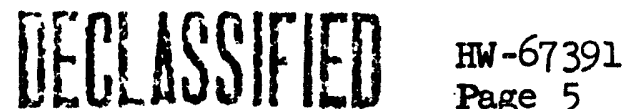

The method developed for determining optimum reactor operating conditions prior to project action is presented in the following stepwise manner.

1. Obtain an estimate of the total number of tubes requiring replacement as a function of the total number of mils corroded from all process tubes. (Note Figure 1). Similar relationships to this have been used by J. R. Young and N. R. Miller to forecast tube replacement losses.

2. Choose any value for "total $\mathrm{mils}$ removed" and divide this by the corresponding number of tubes requiring replacement. This resultant quotient can be called the "equivalent mils removed per tube before replacement"; i.e., for each "equivalent" number of mils of total pile corrosion - one tube will require replacement. (Note Figure 1A).

3. This "equivalent mils removed" value can then be used for the (DMR) term in the optimization model and optimum tube powers, goal exposures, and tube replacement losses (in terms of days lost per calendar day) calculated.

4. Using the calculated tube replacement losses and multiplying by (DMR) and (DTR), the total number of mils removed from all tubes in the reactor for the optimized power level and goal. exposure conditions can be calculated. That is: $\frac{\text { Days lost }}{\text { Calendar day }} \times \frac{\text { mils removed }}{\text { tube }} \times \frac{\text { tubes }}{\text { day }}=\frac{\text { mils removed }}{\text { calendar day }}$

5. The calculated mils removed can then be divided into the assumed (In step calendar day

2) "total mils removed" to obtain the "number of calendar days" required to obtain the assumed total pile corrosion.

6. Thus, if it is assumed that tube replacement project action is scheduled for the "number of calendar days" in the future determined in step 5, the corresponding optimum power level and goal exposures are those determined in step 3 based on the "equivalent mils removed per tube."

7. In step 2 several other assumptions of "total mils removed" can be made and the steps repeated. The results of these steps can be potted and relationships generated for each of the parameters of interest.

Figure 3 is a plot of "equivalent mils removed per tube replaced" versus calendar date. That is, given a specific calendar date for project action, the "equivalent mils" can be determined which, when used in the reactor process optimization program will permit determination of optimum tube powers and goal exposures for reactor operation until the selected project date. Figures 4 and 5 illustrate the calculated optimum goal exposure and tube powers respectively. Figure 6 illustrates the calculated number of tubes that would require removal prior to project action if the reactor is operated at optimum power levels. 


\section{OEECLASSFIED}

\section{APPLICATION OF THIS TECENIAUE TO THE K REACTORS}

\section{General}

To apply this technique to the $K$ Reactors, it is necessary to evaluate the variables which have been mentioned above, i.e., current tube wall thickness, rate at which tube wall is being removed, and rate at which tubes can be replaced. Each of these variables has a pronounced effect upon optimum parameters. The values picked for each of these variables will be briefly discussed below.

The current tube wall thickness at the $K$ Reactors has not been precisely determined. Very little actual data are avallable. All tubes which have been removed to date have had tube minimum wall thicknesses between 52 and 57 mils. A conservative estimate of $50 \mathrm{mil}$ minimum wall thickness was assumed for all tubes by J. R. Young.

The expected date at which tubes will need to be replaced was obtained from J. R. Young and is given as a relationship between the total number of mils corroded from all tubes in the reactor at time $(x)$ and the total number of tubes which will have had to be removed by that time. This relationship is graphically presented in Figure 1. J. R. Young devised this relationship using correlations which have been found to hold true for the old areas.

The rate at which tubes can be removed from the reactor is one of the mosit important variables in the tube replacement loss equation needing evaluation. A comprehensive gfudy of tube removal rates at the old reactors has been made by W. H. Radtke (2). In this study, the average tube replacement rate at the old reactors was found to be 16 tubes per day. This rate includes non-equilbrium losses and other associated losses, 1.e., valving time, etc. It is anticipated that a somewhat higher replacement rate can be realized at the $\mathrm{K}$ Reactors as tube replacement techniques improve; however, there are some other losses to be considered. These losses will come from a decrease in operating efficiency because of water leaks and probologging requirements. The time spent in probologging tubes and finding water leaks will certalnly represent major production losses and must be factored into the overall lose due to tube corrosion. In view of the se additional losses due to tube corrosion, it was felt that a tube replacement rate of 16 tubes per day is realistic and this value was used in the K Area study.

The optimum tube power and exposures determined by the process optimization. :program are, of course, also dependent upon input variables related to terms other than the tube replacement loss term. Some of the se other variables are total flow, average tube flow, charge-discharge rates, ECT, metal quality index $\left(C_{R}\right.$ value), and inlet temperature, Current $K$ Reactor flow and metal quality assumptions, as shown in $\mathrm{HW}-67340(3)$, were used to generate the optimum power levels and goal exposures for this tube replacement loss study. If these assumptions change, calculation of revised optimum parameters would be required.

(3) HW-67340, Graves, SM, "Engineering Bases for Power Levels and Exposures, November, 1960, thru December, 1961," November 7, 1960, (4). 


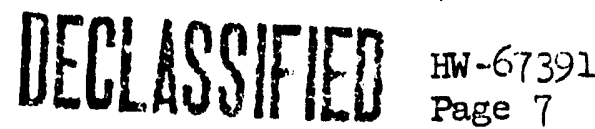

For the graphs presented in this document, an inlet temperature of $12^{\circ} \mathrm{C}$ was chosen because it has been found that the welgnted average monthly corrosion rate is related to an inlet temperature of $12^{\circ} \mathrm{C}$. Thus, the total corrosion for a year can be predicted by using an average inlet temperature of $12^{\circ} \mathrm{C}$.

This analysis does not consider the cost of new tubes or manpower to replace the tubes. These costs, of course, need to be considered in determining the desirable date for a tube replacement project.

\section{Example}

To 1llustrate this method as applied to the $\mathrm{K}$ Reactors, the following example is presented following the steps outlined in the previous discussion.

1. Arbitrar1ly selecting 38,000 total mils removed from Figure 1, curve 1 , ve find that an estimated 600 tubes will require removal.

2. Dividing $\frac{38,300}{600}=63.3 \frac{\text { equivalent mils removed }}{\text { tube repiaced }}$

This "equivalent mils removed" value can aiso be read directly from Figure IA.

3. By programing this "equivalent mil.s removed" value and a 16 tube/day removal rate in the reactor process optimization equation, optimum tube powers, goal exposures, and resultiant tube replacement losses in days lost/celendar day can be obtainea by 709 I3M machine calculation. A plot of resulting optimum tube replacement losses versus "equivalent mils removed" is presented in Figure 2. For the 63.3 "squivalent mils removed" value the IBM program calculated tube replacement loss in days/calendar day is 0.038 .

4. The total mils removed per day under oftimum power level conditions is then $0.038 \times 16 \times 63.3=38.3 \mathrm{rils} / \mathrm{day}$.

5. The total number of days required to remeve the initially assumed 30,000 mils is then $\frac{38}{30} 300=1000$ dars

Since the reference date for the total mils - rumber of tubes removed curve supplied by J. R. Young - is June 1. 1.960, the date for acsumed projest action would be in the spring of 1963.

6. From Figures 4, 5, and 6, the optjmum natural fuel element exposure, optimum maximum tube fower, and related nuriker of tubes requiring removal based on project action in the spring of 1963 is $640 \mathrm{MWD} / \mathrm{T}, 1550 \mathrm{kw}$, and 620 tube: respectively. These are average figures fur the year and are based on a $12{ }^{C} \mathrm{C}$ inlet temperature. Calculritiol of the optimum povers and goal exposures for. each month can be made in a like manner using actual monthiy inlet terperatures.

Results

The immediate resuit of the ibrve calculations is the relationship between a 
project date and optimum "equivalent mils renoved" from each tube replaced, which is shown in Figure 3. Becsuse the data supplied by J. R. Young is believed to be conservative, for comparison purposes the data presented in Figure 1 was adjusted 10 per cent ana 50 per cent in a direction so as to predict increased tube life. That is, the assumption was made that an additional 10 per cent or 50 per cent more internal corrosion would have to occur before the same number of tubes would require removal. These adjusted comparative curves are presented in all the attached graphs.

The use of mixing slugs is belleved to be desirable and will extend tube life. The exact amount of benefit provided by mixing slugs is not known, but the 10 and 50 per cent curves will serve as a guide to evaluate any assumed benefit from mixing slugs.

The shape of the curves in Figures 3, 4, 5, and 6 is governed by the assumption winich has been made concerning the manner in whjch the tubes will come up for replacement. Figure 1 shows that we have assumed that no tubes will be removed until 28,000 mils have been removed from all tubes. Then tubes will come 60 removal very rapialy. This is reflected in all curves to show that up uritii about 900 calendar days from June 1, 1960, no tube replacement loss will be incurred. At that time a very large number of tubes will need to be removed for a relatively small additional amount of corrosion. After about 2000 calerjou: days from June 1, 1960 , we approach a condition of continuous iube replacenent such as is being experienced at the old erees. In esscice, this indicates thet. up until about the first of CY- 1963 negligible tube replacement loss will heve been incurreo, and by $C Y-1966 t_{11} K$ Reactors would require a complete set oi new tubes and would have incurred the maximum amount of tube replacement ioss. Figure 6 was derived from this data and shows the totai number of tubes remover at any given tine.

As already discussed, it is possible with the help of Figure 3 to obtain the optimum tube power and optimum exposure for any project date. The proceaure consists of choosing the "equivalent nils remove "from each tube before replacement from Figure 3 and using this number in the optimizetion equation. The optimum tube power and exposure is then obtained from the 709 progrtm. Th: was dore for a range of project dates and the data are presented in Figures 4 and 5. Figure 4 shows optimum exposure for a range ef project astes from Cy-3,63 to 1967 . Curve $I$ is based upon tube removal dote as presented by J. R. Youris, curve 2 j.s 10 per cent less concervative and curve 31250 per cent less conservative. All curves are based upon $12^{\circ} \mathrm{C}$ irlet. vater temerature. Ls in Figure 3 , the shape of the curves are govermed by the manner in which tubes come ur for replacement (i.e., the shave of Figure 1 ). It is obvious that $1 f^{\prime}$ the tube replecement project aate comes before any tubes need to be replaced, the optimun exposiure will correspond to that for zero tidbe replacement loss, that is, $580 \mathrm{MWD} / \mathrm{T}$. When tubes start to be replaced a large number will come out very rapidly causing the optimum exposures to rise very reptdly, and approach the optimum exposure corresponuing to normei. tuoe replacement loss, that is, $690 \mathrm{MWD} / \mathrm{T}$. 


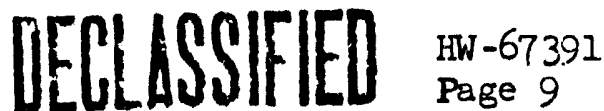

Figure 5 shows the optimum maximum tube power for various project dates. As in Figure 4, the shape is determined by the tube replacement date. Zero tube replacement losses correspond to a optimum tube power of $1640 \mathrm{kw}$ and the norral tube replacement losses correspond to an optimum maximum tube power of $1510 \mathrm{kw}$ at an inlet temperature of $12^{\circ} \mathrm{C}$.

The relationship between optimum power and goal exposure with zero tube removal losses and with normal tube removal losses should be mentioned. The reason for the relatively high tube power and low exposure with zero tube removal loss is this. For a wide range of tube replacement losses the production efficiency related to optimum power levels and exposures remain approximately constant. Thus with zero tube removal loss, tube power can be raised until other losses approach replacing the tube removal loss. These losses, which increase as tube power is raised, are charge-discharge losses and rupture losses. . Previous studies have indicated that, as optimum tube power is increased, a decrease in optimum exposure is required to prevent inordingte rupture losses. This inter.action is more thoroughly discussed in HW-61579(I).

The important point illustrated by Figures 4 and 5 is the very large difference between optimum conditions for zero tube replacement losses and for the normal tube replacement losses. This points out the need to more accurately establish the current condition of $\mathrm{K}$ Area process tubes. Quite significant changes in power levels and exposures might be in order if the exact tube conditions and project date were known.

The need for early tube removal project action is dramatically pointed out ij Figure 6 . Figure 6 shows the number of tubes which will have been removed by any given date. Curve 1 is based upon J. R. Young's data, curve 2 is 10 per cent less conservative, and curve 3 is 50 per cent less conservative. It is obvious that if the major tube replacement project does not come until mid1964, a considerable number of tubes will have had to be replaced.

For the recent presentation of recommended operation plans for the $\mathrm{K}$ Reactors, the project date was assumed to be mid-1964. Optimization runs were made and optimum tube powers and exposures were generated for 1961. These values were presented in $\mathrm{HW}-67340(3)$.

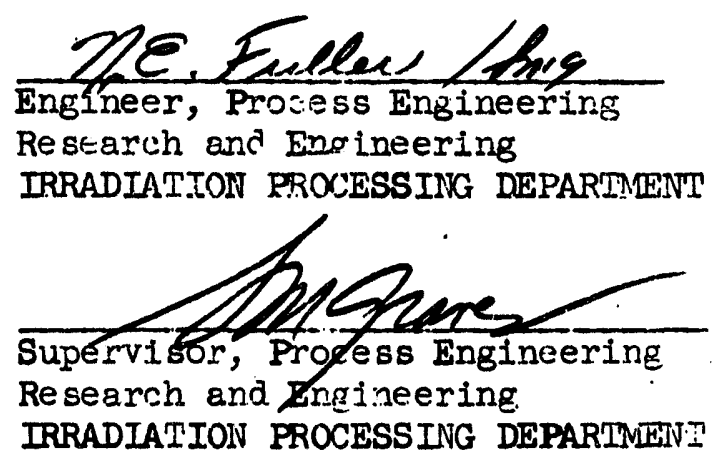

NE Fuller:SM Graves:md 


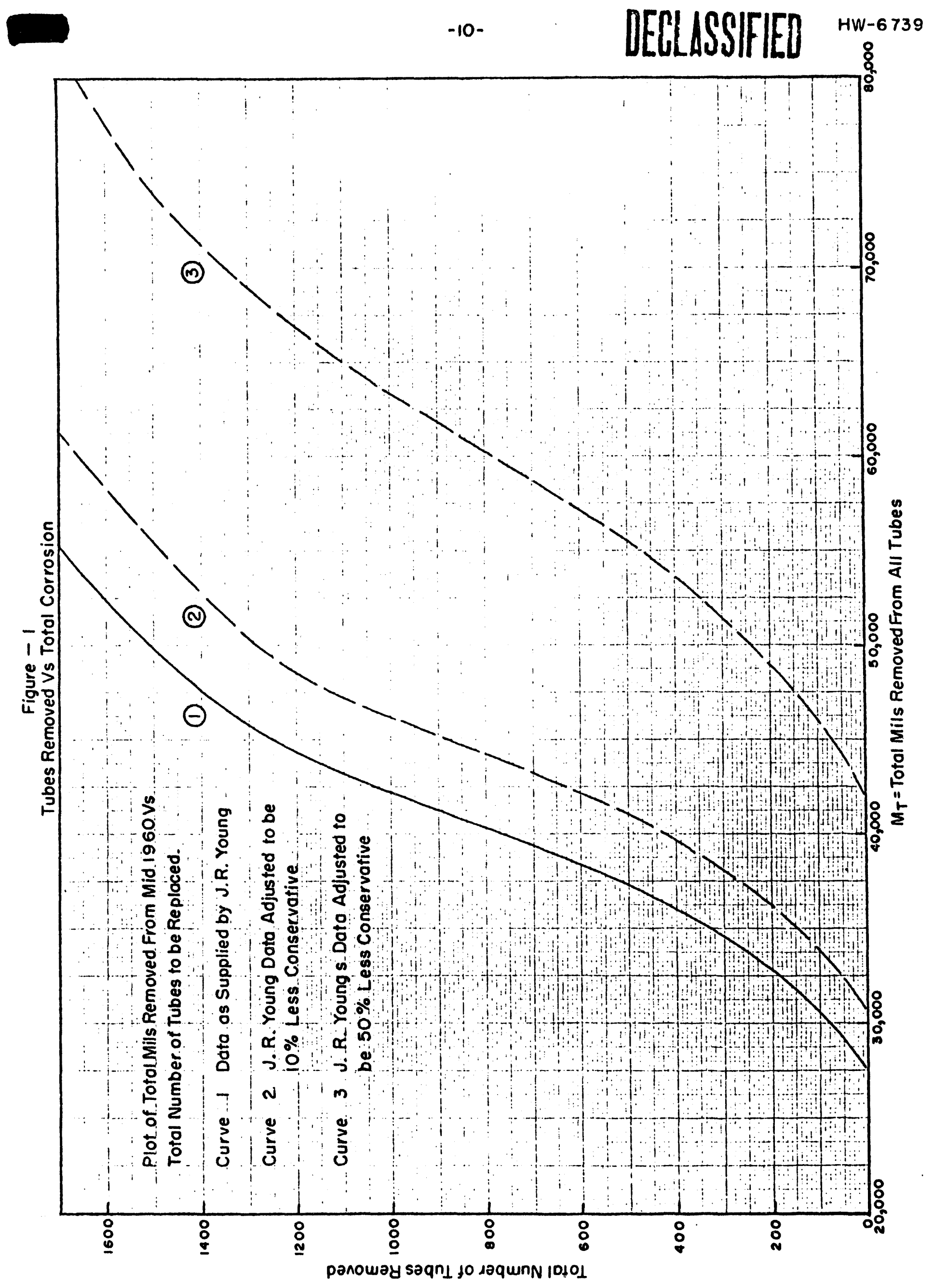




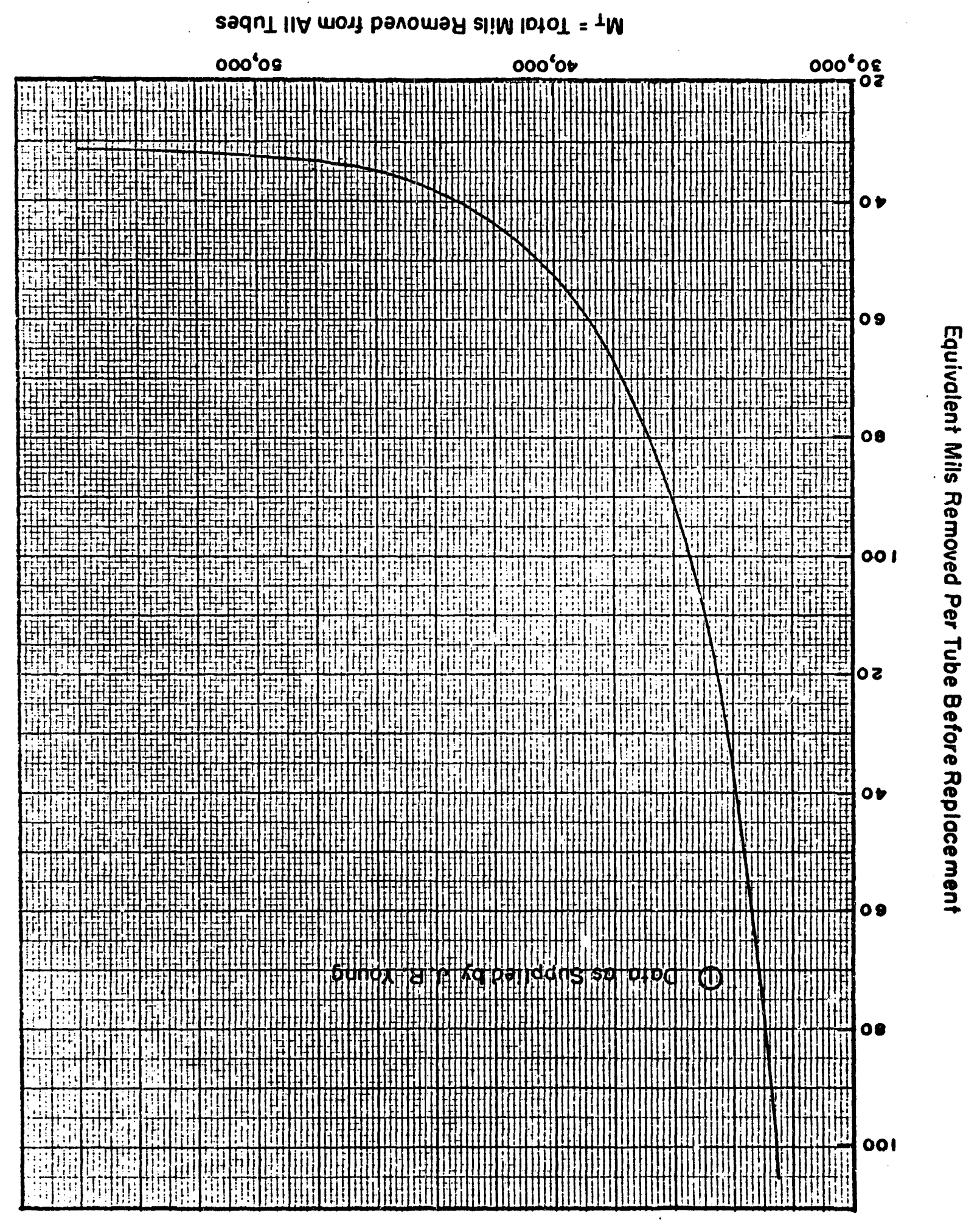

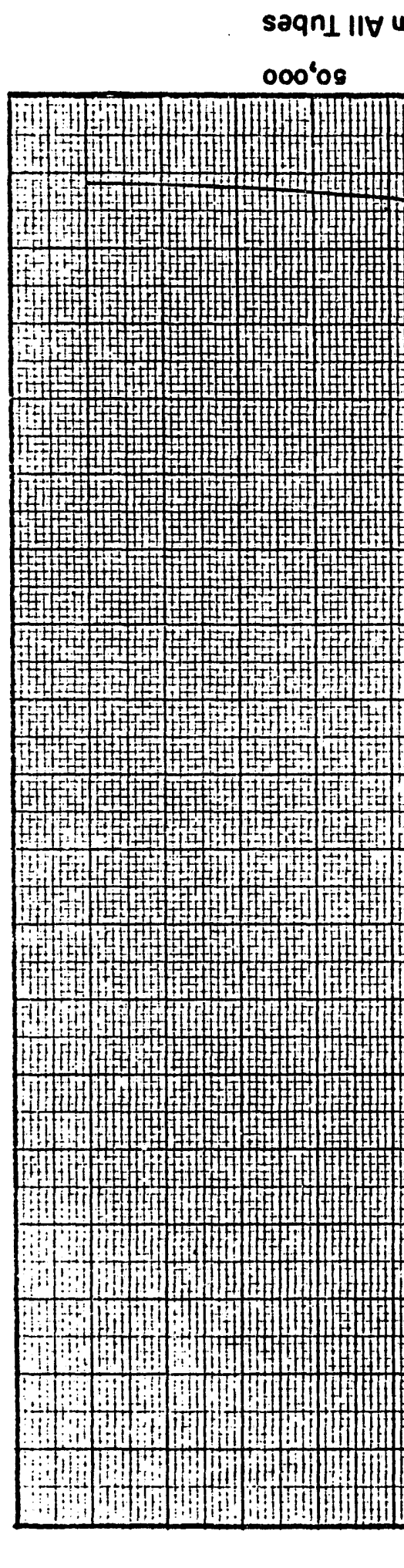

panoway SIIW tUajonịnb

$\forall 1$-aมnb! 


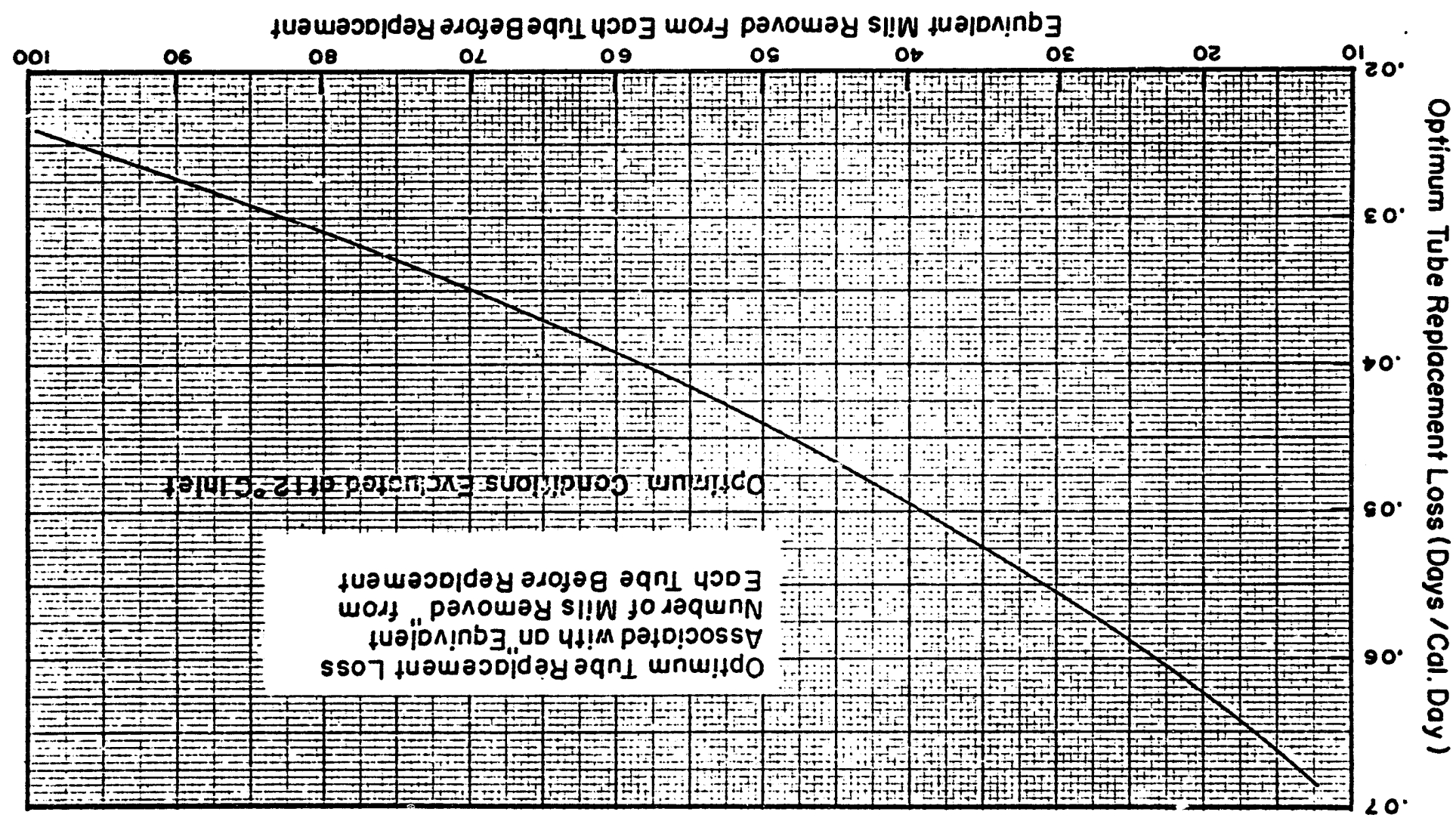

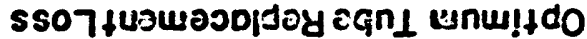

2 - 2 an $5 ! y$ 


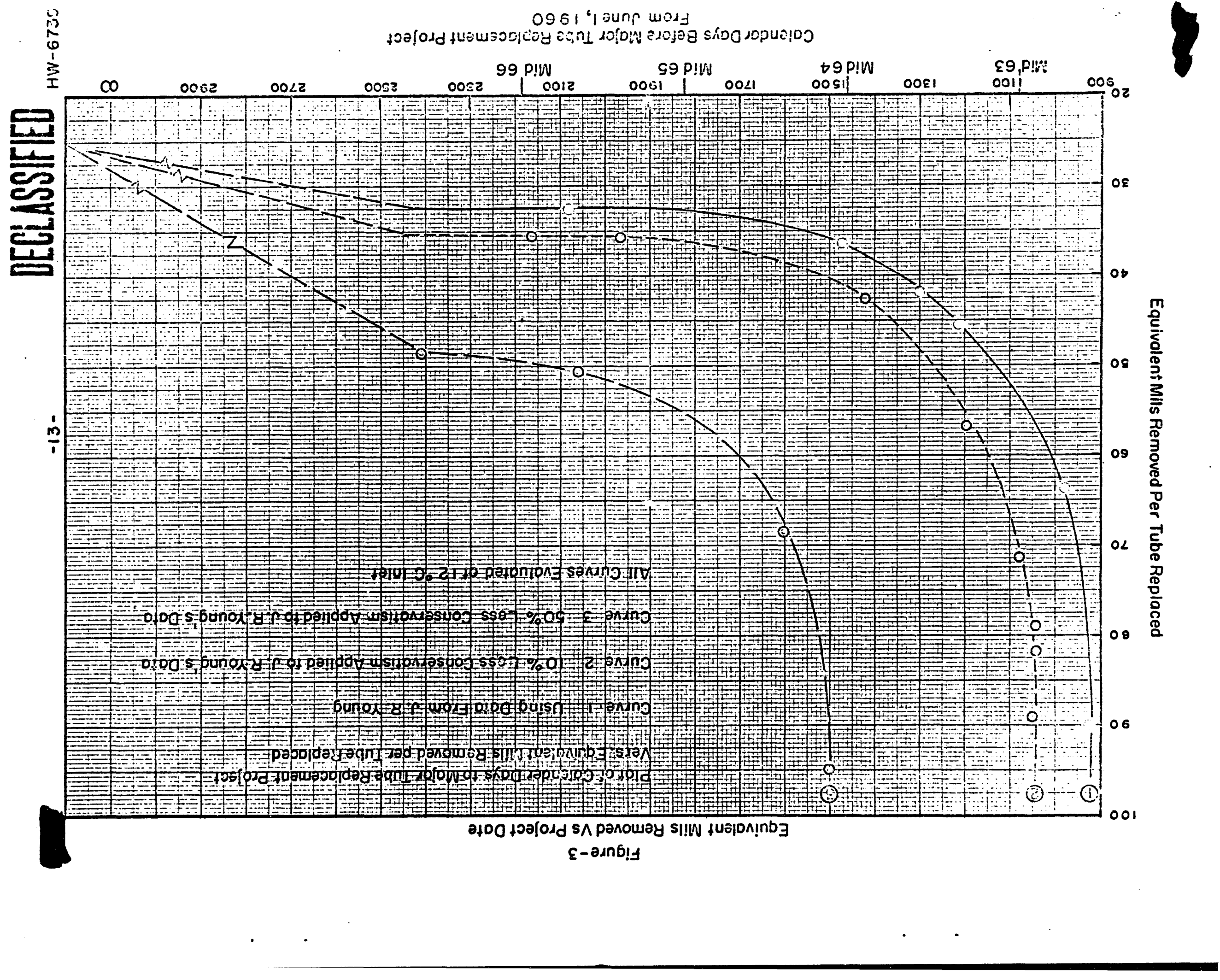


Figure - 4

Optimum Exposure Vs Project Date

(For Notural I \& E Fual Elements)

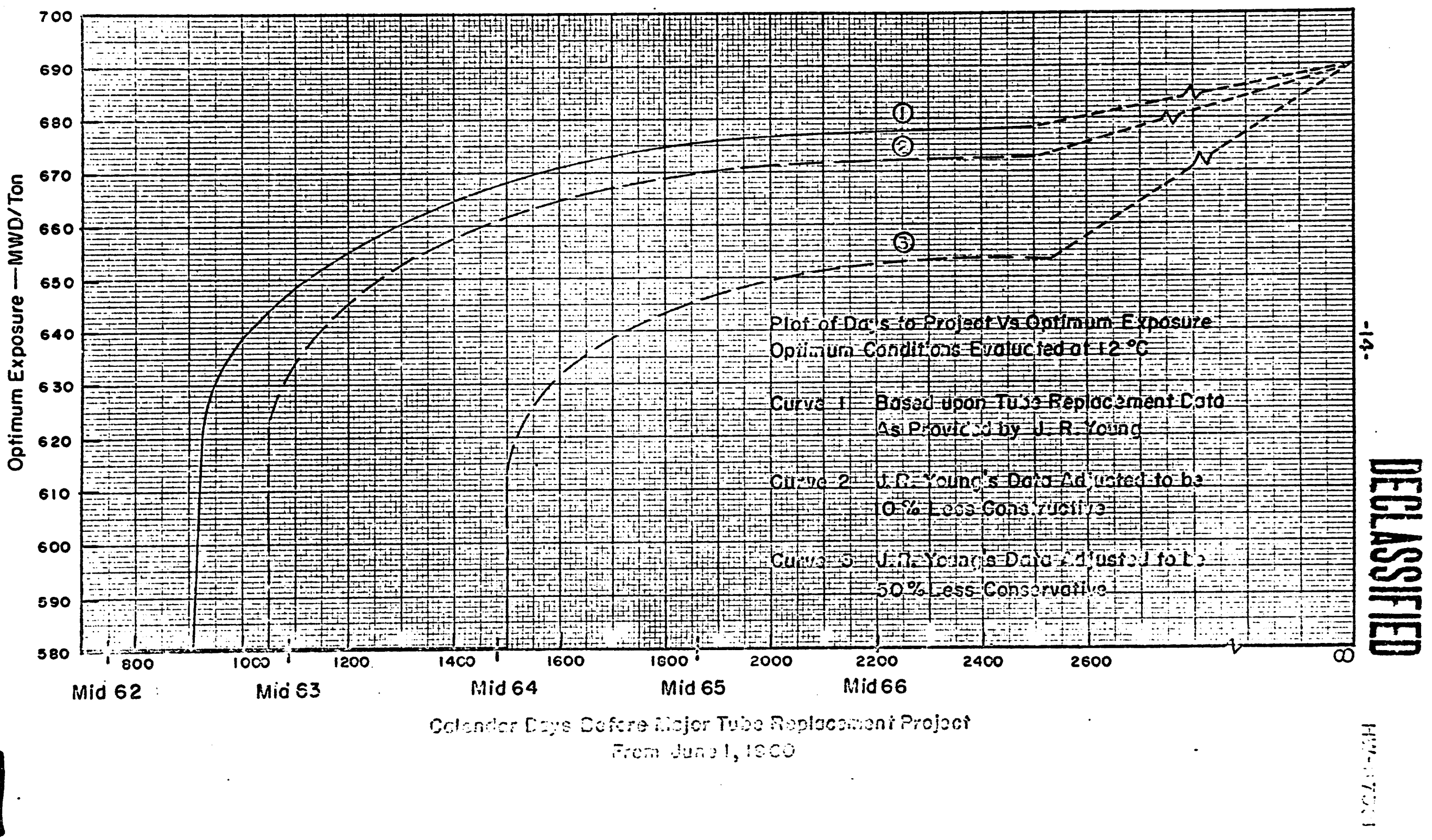


Fianos-

Opiinum Tul: 3 Po $\mathrm{Por}_{\mathrm{s}}$ Projzst Date

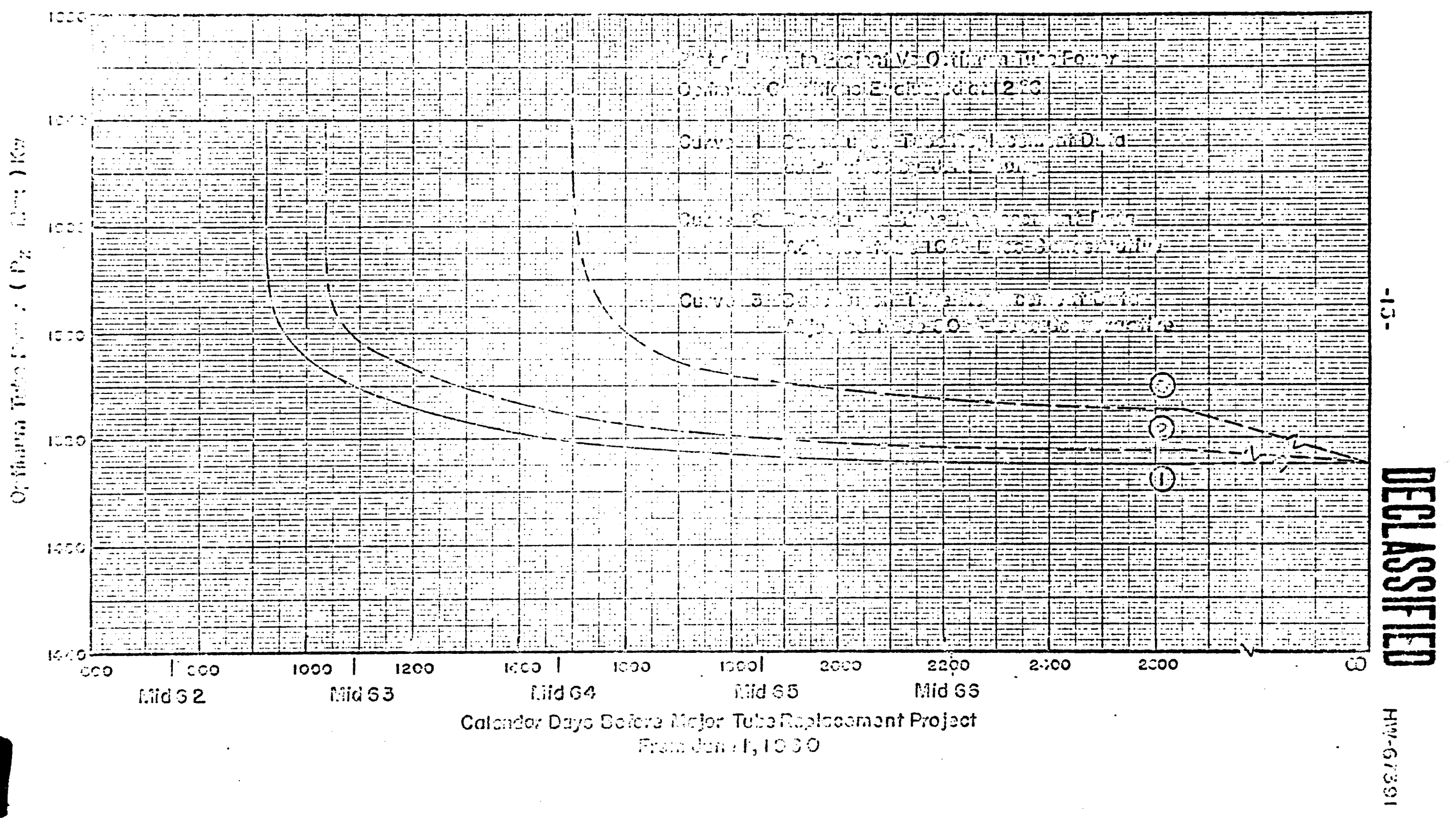




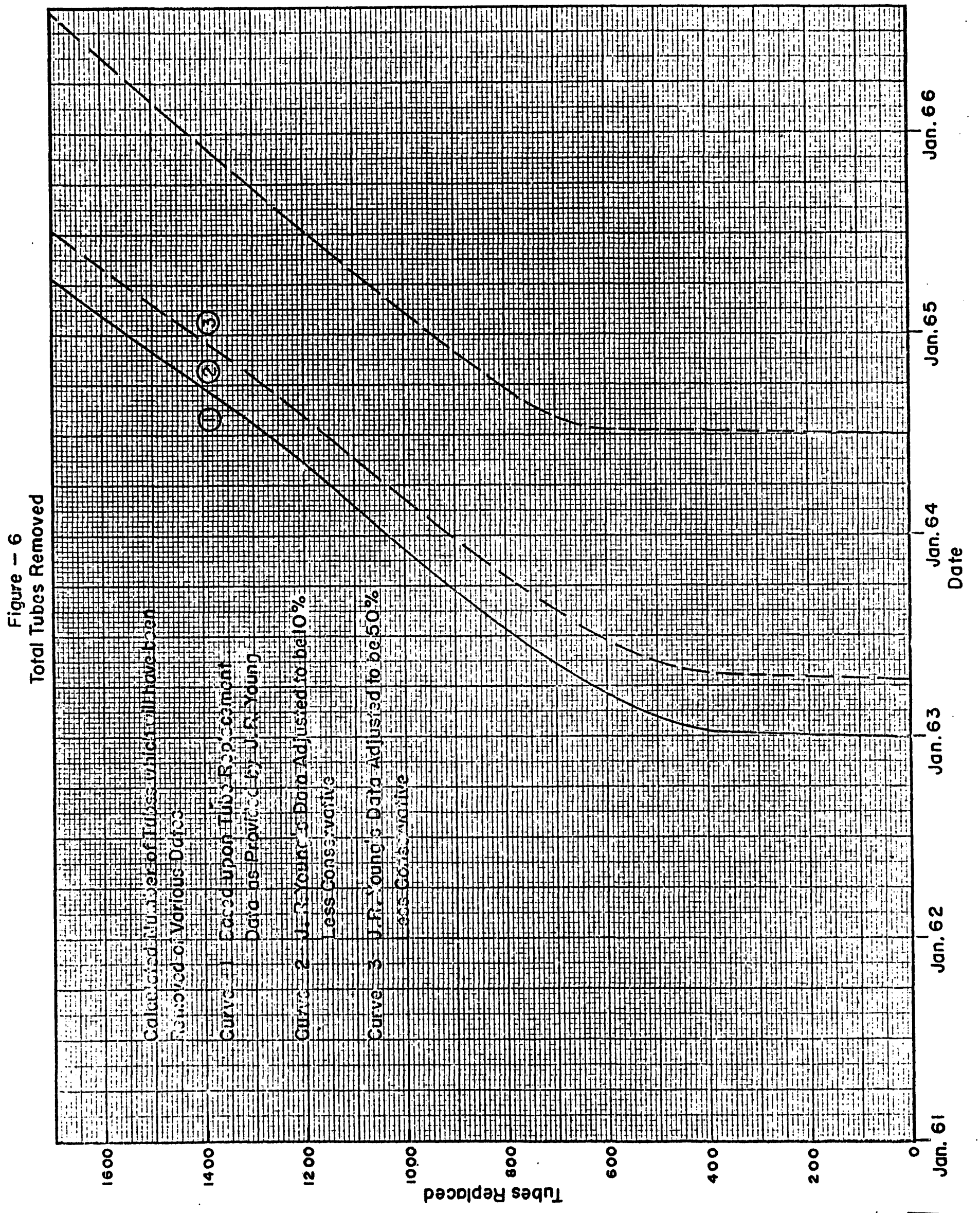



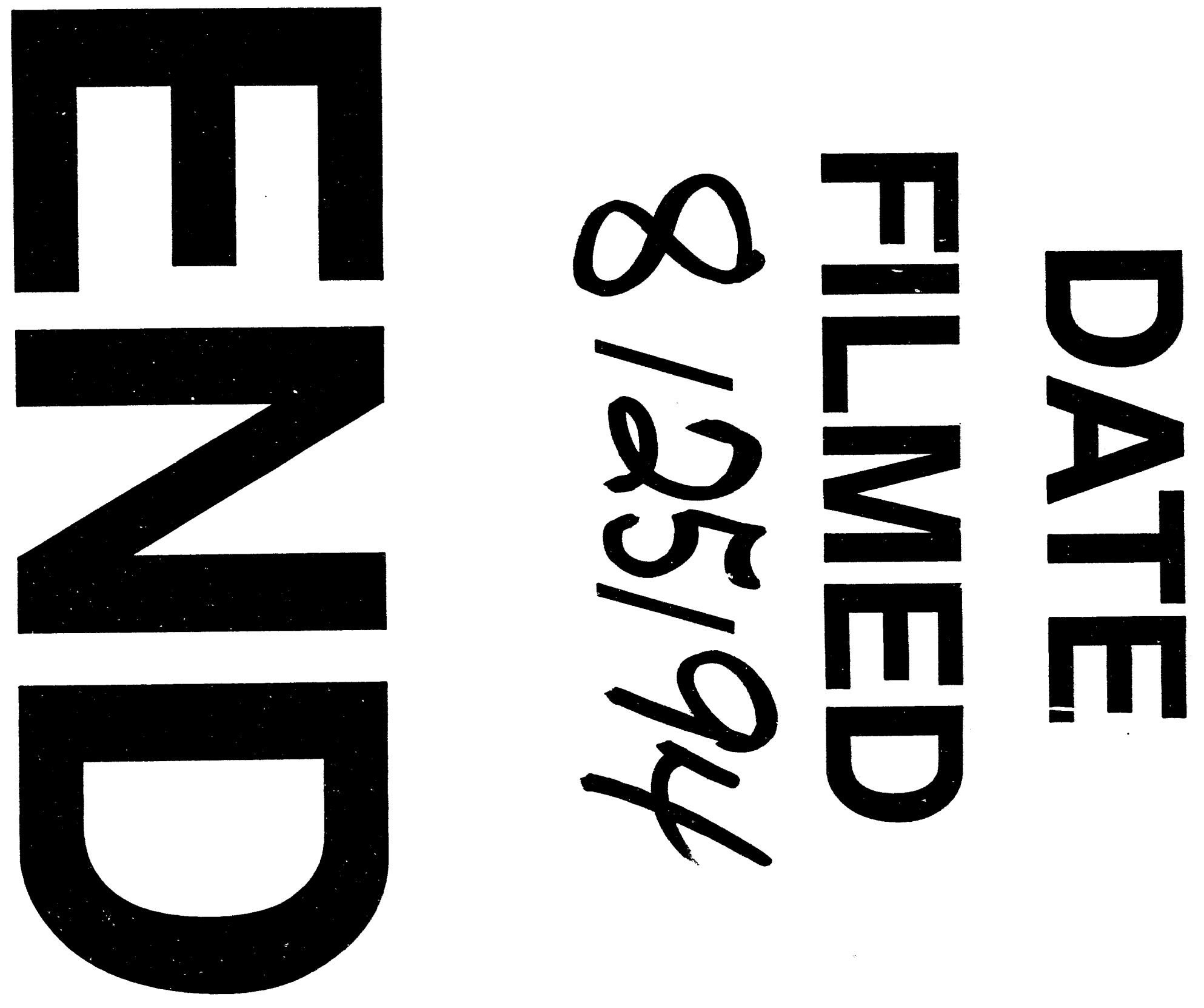
